\title{
Mental Health Camp- A Report
}

\section{Veena Sharma', Vanshika Thukral ${ }^{2}$}

${ }^{1}$ Associate Professor, ${ }^{2}$ M.Sc. Nursing Student, Rufaida College of Nursing, Jamia Hamdard (Deemed to be University), New Delhi, India.

DOI: https://doi.org/10.24321/2349.2880.202016

I $\mathbf{N} \quad \mathbf{F} \mathbf{O}$

\section{Corresponding Author:}

Vanshika Thukral, Rufaida College of Nursing, Jamia Hamdard (Deemed to be University), New Delhi, India.

E-mail Id:

vanshikathukral27@gmail.com

Orcid Id:

https://orcid.org/0000-0001-8374-5996

How to cite this article:

Sharma V, Thukral V. Mental Health Camp- A Report. Ind J Youth Adol Health 2020; 7(3): 26-30.

Date of Submission: 2021-02-05

Date of Acceptance: 2021-03-04

\section{$\begin{array}{llllllll}\mathbf{A} & \mathbf{B} & \mathbf{S} & \mathbf{T} & \mathbf{R} & \mathbf{A} & \mathbf{C} & \mathbf{T}\end{array}$}

Introduction: Mental health camps serve the purpose of enhancing people's awareness about mental health and offer to amend related fallacy and stigma and wrong attitude towards mental illness and people with mental illness. Mental health camps offer a potential to local community to receive affordable help and utilise the available resources to identify, counsel or refer people with mental health issues or in crises situations to community agencies for providing mental health care services.

Material and Methods: A one day free mental health screening, referral and counselling camp was organized on November 20, 2019 in Jamia Hamdard (deemed to be university), Delhi, premises for students and staff. The camp was conducted with due permission from Registrar with a prior notice to the security officer. Standardized inventories for anxiety, depression and stress were administered. After interpretation of scores, those in need of counselling were given one to one counselling, and further referrals, if required, were done by the mental health professionals. A total of 525 students and staff walked in the camp and 86 students were given spot counselling and referral as required. The results from inventories were later analysed and reported.

Result: The analysis of inventories showed that more than $50 \%$ respondents had $50 \%$ probability of developing major stress induced health problems in the near future. More than $2 / 3^{\text {rd }}$ participants had moderate level of stress. The camp helped in dispelling the stigma associated with talking about one's mental health and consolidated the belief that it is okay to talk about one's mental health.

Keywords: Mental Health Camp, Counselling, Students, Anxiety, Stress, Depression

\section{Background}

Young people form precious human resource in every country. WHO defines adolescence as age spanning 1019 years, youth as those in 15-24 years and these two overlapping age groups as 'young people', covering the age group of 10-24 years. ${ }^{1}$ As about 356 million people in India are between 10-24 years, India is a young country with about $30 \%$ of its population being youth. According to WHO, mental health problems account for about $16 \%$ of global burden of diseases in people aged $10-19$ years. ${ }^{5}$ Half of all the mental illnesses begin by the age of 14 , but most cases go undetected and untreated. In terms of burden of disease among adolescents, depression is the third leading cause. Suicide is the second leading cause 
of death among 15-29 year old. Harmful use of alcohol and illicit drugs among adolescents is a major issue in many countries and can lead to risky behaviors (such as dangerous driving). If untreated, these conditions influence children's development, their educational attainment and their potential to live fulfilling and productive lives. ${ }^{7}$

Adolescence and the early years of adulthood are a time of life when many changes occur, e.g., physical changes, leaving school, leaving home, starting college, university or a new job, career. For many these are exciting times and for some, times of stress and apprehension. The increasing use of social media and technologies, while has many benefits, also brings additional pressure and stress to this age group. These stressors and pressures can jeopardize mental well-being and lead to mental health problems.

Important mental health habits- including coping, resilience and good judgement- help adolescent to achieve overall well-being and set the stage for positive mental health in adulthood. ${ }^{6}$ However, many schools lack the necessary support to implement quality mental health evaluation and treatment programs, which is required to improve mental well-being and overall quality of life of adolescents, youth and their families. Adolescent and youth surveys show that teenagers and adults prefer school based mental health screening programs over community based mental health screening programs largely due to decreased stigma associated with school-based programs. Although, community-based screening and referral is also needed, particularly for youth with more severe or complex mental health needs. ${ }^{4}$ Colleges/ universities need to offer some form of mental health awareness and prevention programs that include screening, information and referral. ${ }^{8}$

Keeping this information in the backdrop, we thought of organizing one day mental health screening, referral and counseling camp on November 20, 2019 in Jamia Hamdard premises for students and staff. The camp intended to:

- Destigmatize talking about, and taking stock of one's mental health.

- Acknowledge and identify underlying mental health issues in a non-judgmental space.

- Refer the people to appropriate mental health professionals, if required.

\section{Methods}

In the run-up to the camp, preparations started many days before the camp. We worked out the logistics related to organization of the camp, administrative approvals were obtained for organizing the camp within the university premises. The camp was conducted with due permission from Registrar with a prior notice to the security officer. The venue which allegedly received the maximum footfall in the university was chosen as the site to set up the camp after recede of the premises of Jamia Hamdard. Charts, posters banners carrying messages related to mental health were hand made to display at the camp site for creating awareness and reduce the stigma related to mental health issues. Pamphlets carrying messages on mental health in Hindi and English language were made for distributing to students and staff coming to the camp. We selected appropriate standardized, free and open access anxiety, stress and depression inventories for administration on the day of the camp.

On the day of the camp, banners and handmade posters were displayed in the pavilion set up for the camp. Desks and chairs were set up. From morning 9:30 am till 5:00 pm evening, 525 students and staff walked in the camp. They were administered inventories like:

- $\quad$ Beck's Depression Inventory (BDI)

- Beck's Anxiety Inventory (BAI)

- Emotional Quotient Inventory

- Holmes-Rahe Life Stress Inventory

- Perceived Stress Scale

- Workplace Stress Inventory

- Fagerstrom Test of Nicotine Dependence

As mentioned these inventories were open access and freely available. After interpretation of scores on these inventories, those who were found to be in need of counselling were given spot one-on-one counselling by the mental health professionals and further referrals, if required were also done. Some students voluntarily opted for counselling. Total 86 students were given spot counselling and referral, as required.

\section{Analysis of Inventories}

The students and staff who walked into the camp were briefed that they had 7 inventories to choose from as listed earlier. They could opt for any of those or all of those. A participant information form was compulsory to be filled by every participant so that we could have basic information about the participant, and also to follow up, if required. The inventories were self-administrable and easy to administer, score and interpret. The mental health professionals who organized the camp had the necessary training to administer, score and interpret the scores obtained on these inventories. Each inventory's category wise range of scores were sorted, followed by frequency and percentage of people obtaining the range of scores. The results were drawn using the percentage of students scoring in each range of score.

\section{Result}

This section includes inventories and categories with Category wise range of scores, frequency and corresponding percentage. 


\begin{tabular}{|c|c|c|c|c|}
\hline $\begin{array}{l}\text { S. } \\
\text { No. }\end{array}$ & Inventory and Categories & $\begin{array}{l}\text { Category wise } \\
\text { range of scores }\end{array}$ & Frequency & Percentage \\
\hline \multirow[t]{4}{*}{1.} & Holmes-Rahe Life Stress inventory & & & $n=23$ \\
\hline & $\begin{array}{l}\text { Low amount of life chance and low susceptibility to stress } \\
\text { induced health problems }\end{array}$ & 150 or less & 8 & $34.7 \%$ \\
\hline & $\begin{array}{l}50 \% \text { chance of major stress induced health problem in the } \\
\text { next } 2 \text { years }\end{array}$ & $150-300$ & 13 & $56.5 \%$ \\
\hline & $\begin{array}{l}\text { Increases } 80 \% \text { chance major stress induced health problem } \\
\text { in the next } 2 \text { years }\end{array}$ & 300 or more & 2 & $8.6 \%$ \\
\hline \multirow[t]{4}{*}{2.} & Perceived stress scale & & & $\mathrm{n}=178$ \\
\hline & Low stress & $0-13$ & 27 & $15.1 \%$ \\
\hline & Moderate stress & $14-26$ & 126 & $70.7 \%$ \\
\hline & High stress & $27-40$ & 25 & $14 \%$ \\
\hline \multirow[t]{17}{*}{3.} & Quick Emotional Intelligence Self-Assessment & & & $n=144$ \\
\hline & Emotional Awareness & & & \\
\hline & Area for enrichment: requires attention and development & $0-24$ & 65 & $45.1 \%$ \\
\hline & Effective functioning: consider strengthening & $25-34$ & 69 & $47.9 \%$ \\
\hline & Enhanced skills: use as leverage to develop weaker areas & $35-40$ & 10 & $6.9 \%$ \\
\hline & Emotional Management & & & \\
\hline & Area for enrichment: requires attention and development & $0-24$ & 69 & $47.9 \%$ \\
\hline & Effective functioning : consider strengthening & $25-34$ & 60 & $41.66 \%$ \\
\hline & Enhanced skills: use as leverage to develop weaker areas & $35-40$ & 15 & $10.41 \%$ \\
\hline & Social Emotional Awareness & & & \\
\hline & Area for enrichment: requires attention and development & $0-24$ & 26 & $18.05 \%$ \\
\hline & Effective functioning :consider strengthening & $25-34$ & 97 & $67.36 \%$ \\
\hline & Enhanced skills: use as leverage to develop weaker areas & $35-40$ & 21 & $14.58 \%$ \\
\hline & Relationship Management & & & \\
\hline & Area for enrichment: requires attention and development & $0-24$ & 47 & $32.63 \%$ \\
\hline & Effective Functioning :Consider Strengthening & $25-34$ & 70 & $48.6 \%$ \\
\hline & Enhanced Skills: Use As Leverage To Develop Weaker Areas & $35-40$ & 27 & $18.75 \%$ \\
\hline \multirow[t]{7}{*}{4.} & Beck's Depression Inventory & & & $n=58$ \\
\hline & Normal & $1-10$ & 18 & $31 \%$ \\
\hline & Mild mood disturbance & $11-16$ & 15 & $25.8 \%$ \\
\hline & Borderline clinical depression & $17-20$ & 11 & $18.9 \%$ \\
\hline & Moderate depression & $21-30$ & 11 & $18.9 \%$ \\
\hline & Severe depression & $31-40$ & 3 & $5.17 \%$ \\
\hline & Extreme depression & Over 40 & 0 & 0 \\
\hline \multirow[t]{5}{*}{5.} & Fagerstrom Test For Nicotine Dependence & & & $\mathrm{n}=21$ \\
\hline & Low dependence & $1-2$ & 5 & $23.8 \%$ \\
\hline & Low to moderate dependence & $3-4$ & 4 & $19.04 \%$ \\
\hline & Moderate dependence & $5-7$ & 10 & $47.6 \%$ \\
\hline & High dependence & 8 and above & 2 & $9.5 \%$ \\
\hline
\end{tabular}




\begin{tabular}{|c|l|c|c|c|}
\hline 6. & \multicolumn{1}{|c|}{ Beck's Anxiety Inventory } & & $\mathrm{n}=65$ \\
\hline & Low anxiety & $0-21$ & 39 & $60 \%$ \\
\hline & Moderate anxiety & $22-35$ & 21 & $32.3 \%$ \\
\hline & Severe anxiety & 36 and above & 5 & $7.6 \%$ \\
\hline 7. & \multicolumn{1}{|c|}{ Workplace Stress Inventory } & & $\mathrm{n}=36$ \\
\hline & You handle your job well & $10-30$ & 10 & $27.77 \%$ \\
\hline & Moderately well & $40-60$ & 21 & $58.33 \%$ \\
\hline & Problems need to be resolved & $70-100$ & 5 & $13.88 \%$ \\
\hline
\end{tabular}

23 students and staff filled up Holmes Rahe Stress inventory. The analysis revealed that out of 23, 8 (34.7\%) scored 150 or less meaning that they had low amount of life chance and low susceptibility to stress induced health problems. $13(56.5 \%)$ had $50 \%$ chance of major stress induced health problem in the next 2 years and $2(8.6 \%)$ had $80 \%$ chance of major stress induced health problem.

178 people completed Perceived Stress Scale. Out of 178, more than two-third, that is, 126 (70.7\%) of participants were found to have moderate level of stress on Perceived Stress scale inventory, $27(15.1 \%)$ had low perceived stress and 25 (14\%) had severe perceived stress level.

The Quick Emotional Intelligence Self-Assessment inventory was filled by 144 students and staff. The inventory had four major domains; emotional awareness, emotional management, social emotional awareness and relationship management. Out of 144 respondents, 65 (45.1\%) respondents were found to require attention and development of their emotional awareness and 69 (47.9\%) needed to consider strengthening their emotional awareness. Nearly $50 \%, 69(47.9 \%)$ respondents were found to require attention and development of their emotional management and $60(41.66 \%)$ needed to consider strengthening their emotional management. Majorly, 97 (67.36\%) needed to consider strengthening their social emotional awareness and $70(48.6 \%)$ needed to consider strengthening their relationship management.

The analysis of Beck's Depression Inventory which was filled up by 58 students and staff, showed that $18(31 \%)$ had no signs of depression, and 11 (18.9\%) had borderline clinical depression, 11 (18.9\%) moderate depression, 3 (5.17\%) had severe depression.

21 participants also took Fagerstrom Test for Nicotine Dependence and it was seen that $5(23.8 \%)$ had low nicotine dependence, 4 (19.04\%) had low to moderate dependence, $10(47.6 \%)$ had moderate dependence and only $2(9.5 \%)$ had high nicotine dependence.

In the Beck's Anxiety Inventory, out of 65 respondents who filled up the BAI, 39 (60\%) had low anxiety levels, 21
(32.3\%) had moderate level of anxiety and $5(7.6 \%)$ had severe level of anxiety.

Workplace stress inventory was administered to staff only. It showed that out of 36 staff who filled this inventory, 10 (27.77\%) had low levels of workplace related problems, $21(58.33 \%)$ had moderate levels of workplace stress and $5(13.88 \%)$ had severe workplace stress.

On-the spot guidance and counseling of 86 students and staff that had moderate to high scores on stress, anxiety and depression, dependence on nicotine and low emotional intelligence scores was done. Since counseling is not oneoff, they were advised to follow-up subsequently and referral to mental health professional/ agency was done for further mental health needs and support. It was seen that students and staff had mental health issues varying from academic and career issues, peer pressure, nicotine and other addictions, anxiety, depression, anger, frustrations, insecurities about the future and peer relations, relationship problems, societal expectations and pressures, confusions related to life in general, to list down a few. We displayed interesting and light hearted posters on mental health issues to lighten up the heaviness associated with the issues. Pamphlets in English and Hindi were given to all those who attended the camp. Light and nutritious refreshment were served to all.

\section{Discussion}

The analysis of inventories filled up by students and staff of Jamia Hamdard showed that more than $50 \%$ respondents had $50 \%$ probability of developing major stress induced health problems in the near future. More than $2 / 3^{\text {rd }}$ participants had moderate level of stress. This implies that stress management is the need of the hour if physical and mental well-being and quality of life is to be improved. It was seen that a large majority of respondents needed to work on increasing their awareness and management of their emotions and majority also required to strengthen their relationship management skills.

Auerbach et al. (2016) did a study to assess the prevalence of mental health disorders in college students using World 
Health Organization World Mental Health Surveys. The study findings revealed that out of the $20.3 \%$ of college students with DSM IV diagnosis, $83.1 \%$ had pre-matriculation onset with only $16.4 \%$ utilizing mental health treatment for the same. The study concluded the increased prevalence of mental health issues in college students which is mirroring the findings in current study. (1) Similarly, Selvaraj \& Bhat (2018) did a study to predict the mental health of college students, which concluded that it is important to inculcate psychological strength like emotional management in college students to retain positive mental health which is in line with current study findings. ${ }^{7}$

\section{Conclusions Drawn from Analysis}

The study concludes that stress management is the need of the hour if physical and mental well-being and quality of life is to be improved. Faulty interpersonal communication is the root cause of many conflicts and negatively affects the psychological, social, physical and spiritual health of people. A large number of students and staff were also found to be having anxiety and depression issues, while dependence on nicotine was seen from low to moderate to high intensity. This means that young people need mental health support and robust mental health services in order to address stress, addiction, depression and anxiety. While on-the spot counseling was done for those identified to have mental health problems as described earlier, it is well understood that counseling is never one-off. Counseling services need to be made available, accessible and affordable on continuous basis. A well-trained counselor being available in the university campus will do well to cater to the mental health care needs of vulnerable students and staff. Mental health surveys can be made a regular feature in the university for students and staff. Surveys on substance addictions will also be helpful to assess nicotine, alcohol and other substances addiction among youth as dependence on these is very commonplace among young men and women.

\section{Brief Reflections}

The response received from the participants was really heartening and it was quite a revelation for us organizers also to see that mental health issues are right there with all of us, it's just we need non-judgmental platforms like this camp to actually vent out all our thoughts and feelings which have been ailing us. All we did was lend a patient, listening ear and help with confronting the demons within young students and they were out with their mental maladies. While some walked in the camp sheepishly, some were more than eager and interested to be screened and counseled. We think one day was not sufficient for the camp. This was just a beginning, we intend to create more such platforms in future so that people stop and take some moments out of their busy, stressful lives to 'mind their mind'.

\section{Conflict of Interest: None \\ References}

1. Adolescent Health and Development. WHO Regional Office for south-East Asia. Availablefrom:http:// www.searo.who.int/entity/childadolescent/topics/ adolescent_health/en/index.html

2. Auerbach RP, Alonso J, Axinn WG et al. Mental disorders among college students in the World Health Organization world mental health surveys. Psychological medicine 2016; 46(14): 2955-2970.

3. Dopheide JA. Recognizing and referring at-risk youth. Mental Health Clinician 2013; 2(11): 353-361.

4. Husky MM, Sheridan M, McGuire L et al. Mental health screening and follow-up care in public high schools. Journal of the American Academy of Child \& Adolescent Psychiatry 2011; 50(9): 881-891.

5. Kapur RL, Chandrashekar CR, Shamasundar C et al. Extension of mental health service through psychiatric camps: A new approach. Indian journal of psychiatry 1982; 24(3): 237.

6. Mental Health in Adolescents. Available from: http:// www.hhs.gov/ash/oah/adolescent/development/ mental-health/index.html

7. Selvaraj PR, Bhat CS. Predicting the mental health of college students with psychological capital. Journal of Mental Health 2018; 27(3): 279-287.

8. World Mental Health Day on National Health Portal, published on October 03, 2018. Available from: nhp. gov.in/world mental health day. 